se a phalanx of miniature spears. nother lichen that attracted us was light-green wonder of beauty with se-like tips of crimson.

I tossed a large, round clump of ey-green lichen to Kathryn. Here," I suggested, "A hat."

"To go to the Ladies Meeting ith," Micheal put in quickly.

The afternoon passed very quickly, d all too soon it was time to leave.

A small flock of Mallards rose into the air from near the dark pyramid of a muskrat house. As we neared home, a Blue Jay scolded from the row of dead sunflowers along the garden. And then, catching our instant attention, a small, plump bird with rose-flushed underparts and a striking grey patch on its head, hopped atop a rail fence. It was a Greycrowned Rosy Finch.

It had been a pleasant hike, and to help us remember it we would have a few jars of spicy cranberry jelly.

\title{
Rhapsody in June
}

\section{By ELIZABETH CRUICKSHANK, Regina}

The choice of the most spectacular gment of the province, the Cypress lls, for the summer meeting of the N.H.S. was a happy one. Rain had ven a fresh-washed smell of forest d rich earth to make heady atmosere for the motorcades that conrged on the park.

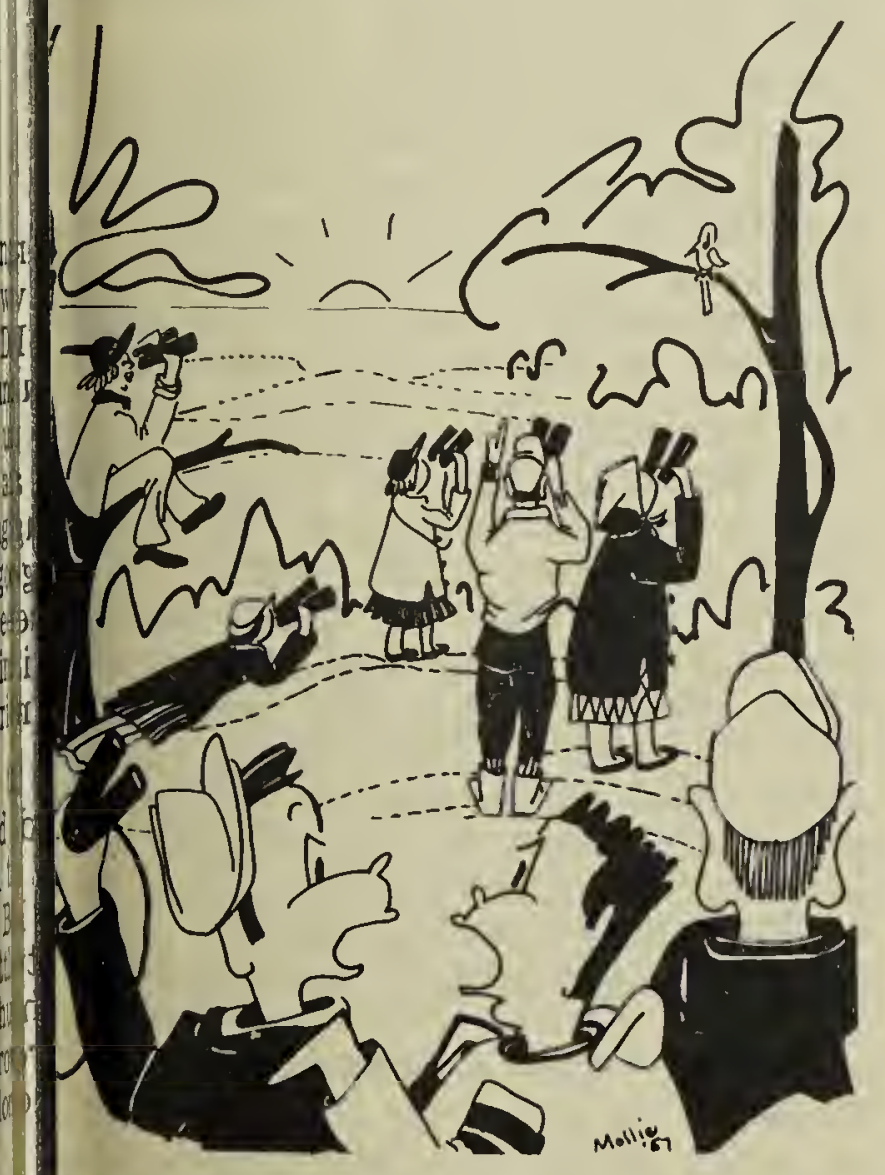

From the crisp hour of dawn ders and botanists were abroad on yages of discovery. A Maryland llow-throat set the mood at that rly hour, a melodic mood that was accompany us through the whole it - "witchery, witchery, wit-
Pink-sided juncos were numerous, one mother leading us to her nest in a grass-curtained hollow in the roadside. A red-breasted nuthatch disclosed his home too, a tiny hollow in the tree trunk beside Mr. Budd's cabin. Over a meadow we followed an ovenbird who called "teacher, teacher, teacher" to friends so glad to see her.

An exhilarating argument about the identification of a plain little warbler must have made it feel like a prima donna, as it sang and bowed on its tree-top stage before the crowd of dedicated birders. Being a Rocky Mountain orange-crowned warblerits crown not on display - it was quite at home in the aspen forest.

A thrilling experience was sighting a lazuli bunting, a Blue Boy picture framed in spruce wood with a cathedral of pines for a background.

On the deep sponge of humus on the forest floor we found orchids not named for their odd and beautiful blossoms but for their odd-shaped roots, - coral root. Some had spotted blossoms, others striped, but all stood in groups, their purple-madder thick stems conspicuous in the subdued light.

Shining arnica reflected the sun that found its way among the pines. to make little pools of light on the burnt-orange pine needle carpet.

From the edge of the road leopard frogs hopped out of our way to the brook that trilled happily as it tumbled in and out of willow and rose 


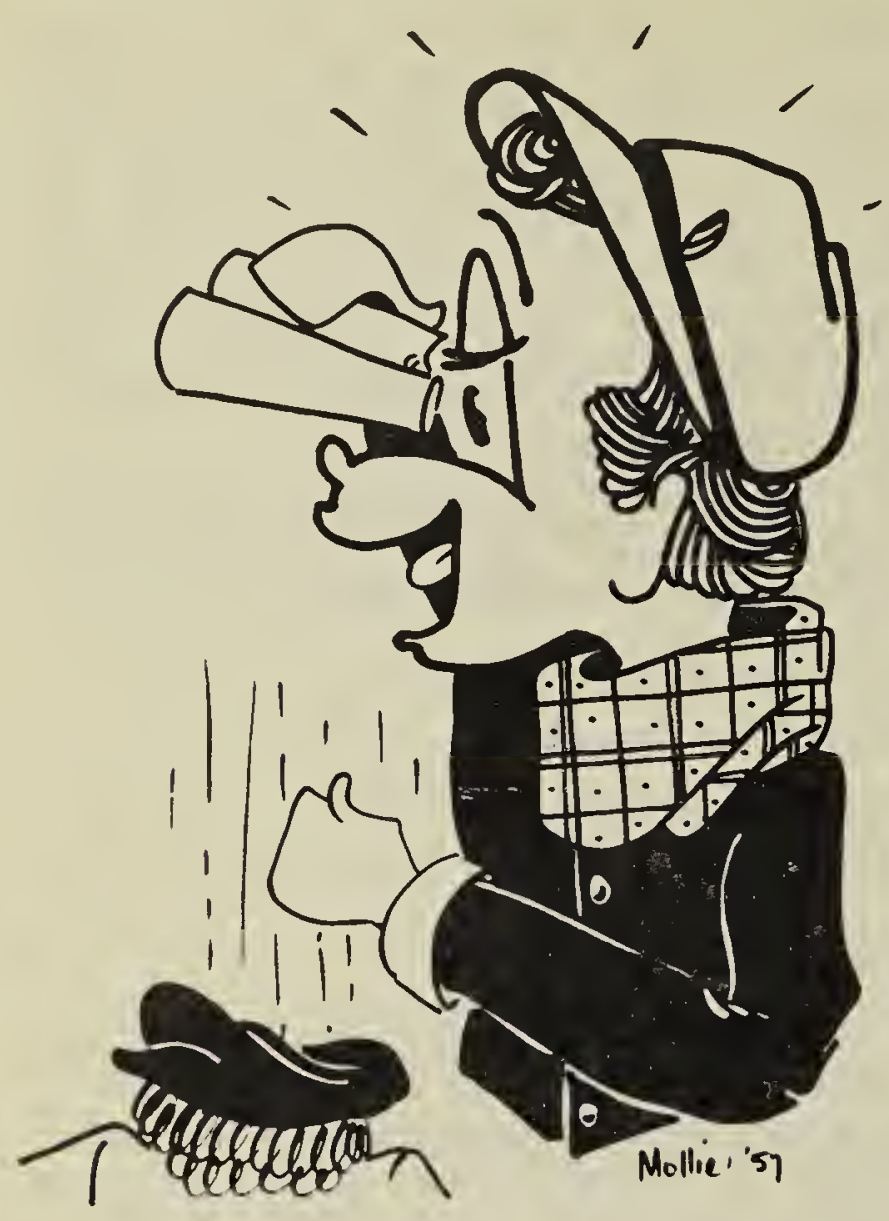

shrubbery on its way to feed Loch Leven.

Although we had begun the morning in definite groups, we found ourselves by noon all mixed up, some of us even lost. But all had made new and exciting friends. The dining hall was full of excited voices: "Rose-pink pussy-toes"; "Bishop's Cap took me back to Ontario"; "Indian paint brush and larkspur" and so on and on. We had considered the lilies of the field and found them satisfyingly lovely. And the bird check lists were discussed, exchanged, argued and gloated over!

The park offered too many features to cover in one weekend. So, some members visited the nesting site of the trumpeter swans; some drove to Bald Butte; some had a stirring ride in a jeep with the fire warden to see Hidden Valley, Lonepine Creek and glorious blue hills in the distance.

The spirit of the open range was symbolized for all of us on the drive to Cypress Lake when we heard the musical, clear, carefree and prolonged call of the long-billed curlew. As it landed within our sight we wondered if it, with other large beautiful birds, would just remain in our memories, its call to become the strange sad cry of a bird nearing extinction? To complete the picture antelope cantered free and fearless along the valle: floor.

In a tiny lake, Wilson's phalarope swam in dizzy circles: clockwise the counter-clockwise. To vary thei activity and menu they ran alon the shore catching flies, a difficul procedure with their long narrov bills. We have seen great blue her ons, too, expertly hawking insect though their long sabre bills seer poorly adapted for fly-catching.

In the evening, naturlists forgc the heat and backless benches in th crowded hall as they plied Bruc McCorquodale with questions afte his engrossing address on the foss mammals of Cypress Hills.

Coffee time allowed exchange experiences and formulating of plar for sunrise excursions in this excer tional area.

Friends new and old said good-by with the hope of meeting again ne: year at Emma Lake. Mr. Herms Chapman, our distinguished visito said he was keeping a list of frien. instead of birds on this trip. It w: such a pleasure to have him with from South Dakota.

We had two regrets - one that: the members of the S.N.H.S. cou not have been there to share $t]$ wonders of the park, and the men ories; and the other that there $w$ no time to get together in worksh sessions to discuss our new finds.

It was not just the birds and pla and pictures, nor the amazing pla but the generous help of the muse directors and their staff, of expert leaders in their differ fields, and of the committee memb from Skull Creek and Regina $y$ had thought of everything, the $p$ ience and consideration of the $p$ superintendent and his staff any one of these things but all cc bined made the safari to Cypr Hills an idyl long to be cherishec

Rupert Brooke knew how each us felt:

Still may Time hold some golc space

Where I'll unpack that scented st Of song and flower and sky and $f$ And count and touch and turn th o'er. 